\title{
Application of Semi-Mechanistic Pharmacokinetic and Pharmacodynamic Model in Antimicrobial Resistance
}

\author{
Kun Mi ${ }^{1}{ }^{1}$, Kaixiang Zhou ${ }^{2} \oplus$, Lei Sun ${ }^{1}$, Yixuan Hou ${ }^{2}$, Wenjin $\mathrm{Ma}^{2}$, Xiangyue $\mathrm{Xu}^{3}{ }^{3}$, Meixia Huo ${ }^{2}$, Zhenli Liu ${ }^{1,2,3}$ \\ and Lingli Huang $1,2,3, *$
}

1 National Reference Laboratory of Veterinary Drug Residues (HZAU), Wuhan 430000, China; mikun@webmail.hzau.edu.cn (K.M.); sunlei23@webmail.hzau.edu.cn (L.S.); liuzhli009@mail.hzau.edu.cn (Z.L.)

2 MAO Key Laboratory for Detection of Veterinary Drug Residues, Huazhong Agricultural University, Wuhan 430000, China; flyingkai@webmail.hzau.edu.cn (K.Z.); hyx97@webmail.hzau.edu.cn (Y.H.); mawenjin@webmail.hzau.edu.cn (W.M.); HuoMeixia@webmail.hzau.edu.cn (M.H.)

3 MOA Laboratory for Risk Assessment of Quality and Safety of Livestock and Poultry Products, Huazhong Agricultural University, Wuhan 430000, China; xuxiangyue@webmail.hzau.edu.cn

* Correspondence: huanglingli@mail.hzau.edu.cn

check for updates

Citation: Mi, K.; Zhou, K.; Sun, L.; Hou, Y.; Ma, W.; Xu, X.; Huo, M.; Liu, Z.; Huang, L. Application of Semi-Mechanistic Pharmacokinetic and Pharmacodynamic Model in Antimicrobial Resistance. Pharmaceutics 2022, 14, 246. https://doi.org/10.3390/ pharmaceutics14020246

Academic Editor: Im-Sook Song

Received: 8 December 2021

Accepted: 4 January 2022

Published: 21 January 2022

Publisher's Note: MDPI stays neutral with regard to jurisdictional claims in published maps and institutional affiliations.

Copyright: (C) 2022 by the authors. Licensee MDPI, Basel, Switzerland. This article is an open access article distributed under the terms and conditions of the Creative Commons Attribution (CC BY) license (https:// creativecommons.org/licenses/by/ $4.0 /)$.

\begin{abstract}
Antimicrobial resistance is a major public health issue. The pharmacokinetic/pharmacodynamic (PK/PD) model is an essential tool to optimize dosage regimens and alleviate the emergence of resistance. The semi-mechanistic PK/PD model is a mathematical quantitative tool to capture the relationship between dose, exposure, and response, in terms of the mechanism. Understanding the different resistant mechanisms of bacteria to various antibacterials and presenting this as mathematical equations, the semi-mechanistic PK/PD model can capture and simulate the progress of bacterial growth and the variation in susceptibility. In this review, we outline the bacterial growth model and antibacterial effect model, including different resistant mechanisms, such as persisting resistance, adaptive resistance, and pre-existing resistance, of antibacterials against bacteria. The application of the semi-mechanistic PK/PD model, such as the determination of PK/PD breakpoints, combination therapy, and dosage optimization, are also summarized. Additionally, it is important to integrate the PD effect, such as the inoculum effect and host response, in order to develop a comprehensive mechanism model. In conclusion, with the semi-mechanistic PK/PD model, the dosage regimen can be reasonably determined, which can suppress bacterial growth and resistance development.
\end{abstract}

Keywords: semi-mechanistic PK/PD model; antimicrobial resistance; mathematical equation; dosage regimen

\section{Introduction}

The emerging antimicrobial resistance (AMR) of bacteria threatens clinical therapeutics. The selective pressure exercised by the misuse and abuse of antimicrobials is an important consideration for the antimicrobial industry. In addition, the use of antimicrobials in animals has been linked to a rise in AMR infections in both animals and humans. AMR significantly increases morbidity, mortality, hospital length of stay, direct healthcarerelated costs, and the indirect societal costs of infections [1]. There is also a higher excess expenditure of $\$ 20$ billion in annual health care costs and $\$ 35$ billion in societal costs due to AMR [2]. Without the effective prevention and control of AMR, it is assumed that AMRrelated deaths will increase from 700,000 to 10 million by the 2050s; thus, it is essential to limit the emergence and spread of AMR.

The pharmacokinetic/pharmacodynamic (PK/PD) model is a recognized tool for determining the dosage regimen and guiding clinical medication. The PK/PD model of antimicrobial agents can describe the triangular relationship between the potency of a drug against a micro-organism, subject exposure to a drug, and drug effects [3] and 
contributes to the adjustment and optimization of dosage regimens, aiming to provide enough antibacterial effect for an infection caused by drug-resistant bacteria [4]. The PK/PD model of antimicrobials has been categorized by three PK/PD indices, which are comprised of a summary endpoint of drug exposure correlated with the minimum inhibitory concentration (MIC). The standardized notations for the PK/PD indices are $\mathrm{AUC}_{0-24 \mathrm{~h}} / \mathrm{MIC}, \mathrm{C}_{\max } / \mathrm{MIC}$, and $\mathrm{T}>\mathrm{MIC}$, where $\mathrm{AUC}_{0-24 \mathrm{~h}} / \mathrm{MIC}$ is the ratio of the area under concentration related to the MIC within a $24 \mathrm{~h}$ period, $\mathrm{C}_{\max } / \mathrm{MIC}$ is the maximum concentration related to the MIC, and T > MIC is the cumulative percentage of the $24 \mathrm{~h}$ that the concentration is above the MIC. Over recent decades, the PK/PD indices have been applied as a cornerstone of dose selection for antibiotics; however, this approach is associated with several drawbacks:

(1) The limitation of the MIC. The MIC is determined at only one time point (over a $16-18 \mathrm{~h}$ period), with a low initial inoculum (i.e., usually in the absence of resistant populations), and utilizing a constant inoculum antimicrobial concentration, which is opposed to the dynamic changes in the in vivo condition [5]. The MIC-based method ignores the time-course of bacterial killing and is unable to predict the emergence of resistance. Additionally, with the two-fold dilution technique and visual inspection, measured and subjective errors may exist in the MIC results, inducing substantial uncertainty and variability. Thus, MIC is not an appropriate quantitative PD index to characterize concentration-effect relationships [6].

(2) $\mathrm{PK} / \mathrm{PD}$ indices is established by correlating the reduction in bacterial count $24 \mathrm{~h}$ after an initial inoculum count [7]. It is an empirical method to select the best PK/PD index to predict the in vivo clinical efficacy and determine the optimal dosage regimen (as shown in Figure 1). The endpoints lack detailed information about the time course of the individual PK and PD processes, and the PK/PD indices are highly reliant on the MIC; thus, the drawbacks of the MIC (static concentration and uncertainty) are propagated in the indices. The PK/PD indices also vary between different patients, diseased conditions, and MIC uncertainty. For example, the most correlated PK/PD index of cefuroxime, a time-dependent antimicrobial, changes between $\mathrm{T}>\mathrm{MIC}$ and AUC/MIC at different conditions [8]. Additionally, the dosage regimen, determined by the PK/PD index, cannot provide information about resistance. Thus, applying PK/PD indices to design the dosage regimen seems questionable [9].

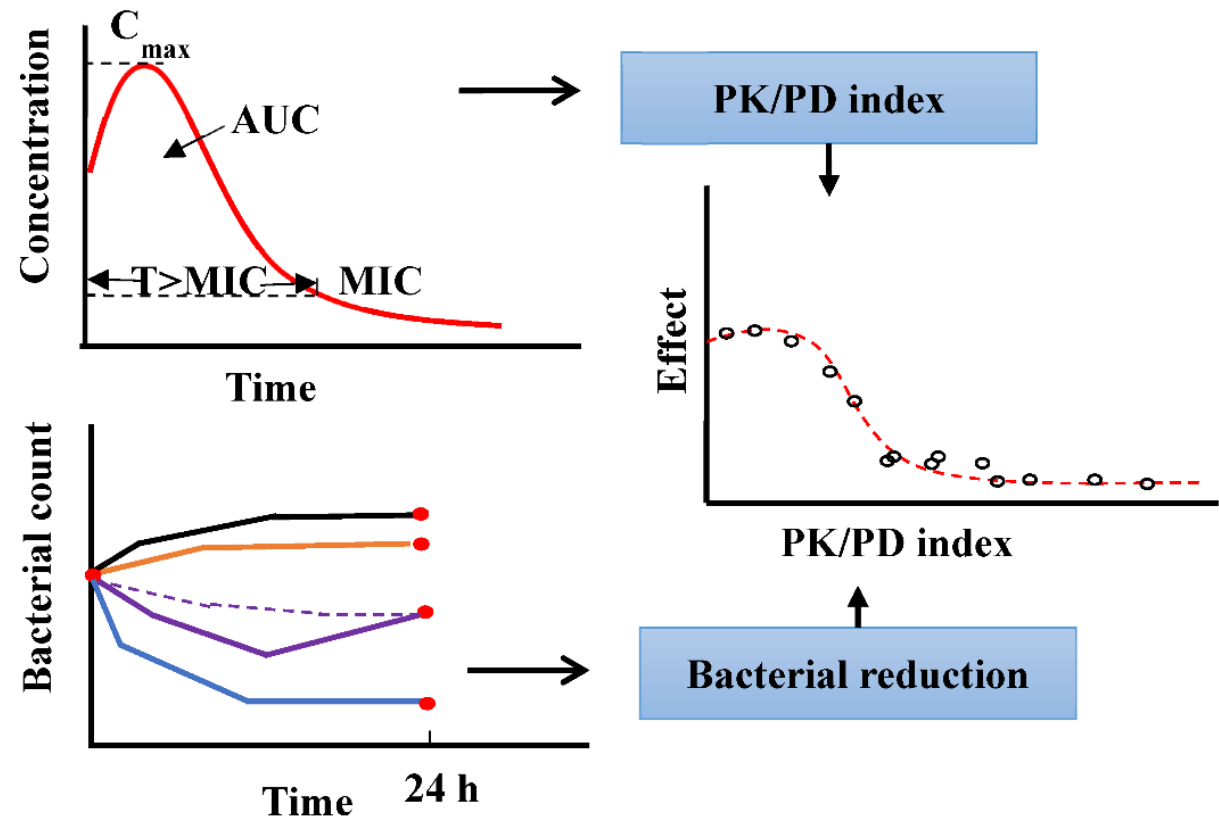

Figure 1. Method to derive the PK/PD index using the empirical PK/PD model. 
Mathematical models are important decision-supporting tools in medicine and public health [7]. An in silico trial based on the PK/PD model can serve as primary evidence for the approval of a labelled dosage regimen for one patient. In addition, the US Food and Drug Administration (FDA), European Medicines Agency (EMA) and Centre for Drug Evaluation of China encourage the adaptation of mathematical models for drug research and development [10].

A semi-mechanistic PK/PD model was applied to alleviate the shortcomings of the empirical model. The semi-mechanistic PD model can parameterize the processes of bacterial growth and antibacterial effect and can be integrated with the PK model to simulate the growth, death, and resistance emergence of the bacterial population under different antibacterial exposures. Compared with the mechanistic PK/PD model, the semi-mechanistic PK/PD model focuses on the macroscopic description of the microbial system. As an example, for AMR, the mechanistic PD model is expert in describing the process of protein function, which can influence the antimicrobial effect, and the semimechanistic PK/PD model can simply the process and only describe the antimicrobial resistance phenomenon. A semi-mechanistic PK/PD model, where prior mechanistic understanding of the system is coupled with experimental data, may offer additional information in the model extrapolations compared to an empirical model, while requiring less prior knowledge [11]. The semi-mechanistic PK/PD model is devoted to improving our understanding of the emergence, development, and spread of AMR and is a valuable tool for optimizing the dosage regimen of antimicrobial agents.

In this review, we introduce several semi-mechanistic models and analyzed different factors that would influence the assessment of antibacterial effect, such as the inoculum effect and host response. Additionally, we summarize the application of various semimechanistic PK/PD models in alleviating the emergence of AMR.

\section{Components of Semi-Mechanism PK/PD Model}

Typically, a semi-mechanistic PK/PD model is composed of three basic components: (i) a component describing the PK of the drug, (ii) a component describing the bacterial kinetics, and (iii) a component describing the antibacterial effect.

The PK model is applied to describe the adsorption, distribution, metabolism, and excretion progress in the body. The compartmental model represents the body as a system of one or more compartments, which does not correspond to the physiological and anatomical mechanism [12]. For the mechanistic model, the physiological-based PK (PBPK) model describes the processes of chemical absorption, distribution, metabolism, and excretion (ADME) based on physiological and biochemical mechanisms [13]. Population PK modelling aims to use the techniques of model development to describe the population of interest. The process of modelling seeks to identify covariates that may be associated with potential sources of variability, particularly between individuals of relevance [14]. The ability to extrapolate dose and simulate the concentration-time curves using the mechanistic model is a great advantage.

In this review, we overview the components of bacterial growth and antibacterial effect, focusing on the AMR mechanisms.

\subsection{Bacterial Growth Model}

The simplest model, which describes the bacterial kinetics by a first-order rate constant for bacterial growth $\left(k_{\text {growth }}\right)$ and a first-order rate constant for bacterial death $\left(k_{\text {death }}\right)$, is shown in the Equation (1) [15]. B is the number of bacteria count by agar determination. The first-order rate constant for observed growth $\left(k_{\text {net }}\right)$ is calculated as $k_{\text {net }}=k_{\text {growth }}-k_{\text {death }}$, since it is difficult to separate micro-organisms for growth or death using the PD experiment.

$$
\frac{d B}{d t}=k_{n e t} \times B
$$


A saturable non-linear model is also used to describe bacterial growth, as Equation (2) shown as Equation (2), where $V G_{\max }$ is the bacterial maximum growth per time and $B_{50}$ is $B$ at which the bacterial growth is half-maximal [16].

$$
\frac{d B}{d t}=\left(\frac{V G_{\max }}{B_{50}+B}\right) \times B
$$

In the absence of an antimicrobial, bacteria grow exponentially until they reach a stationary bacterial level. It has always been thought that a limitation of nutrients leads to the stationary level. A logistic function can be used to describe capacity-limited growth curves, where $B_{\max }$ is the maximum number of bacteria in the system, as Equation (3) shown [17]. However, the application of capacity-limited micro-organism growth to capture the time course of bacteria using the in vitro static and dynamic model indicated that nutrients are not the main reason [8].

$$
\frac{d B}{d t}=k_{\text {net }} \times \frac{B_{\max }-B}{B_{\max }} \times B
$$

Another approach to model capacity-limited growth is the division of micro-organisms into two subpopulations, one being a growing subpopulation and the other being a resting subpopulation. Bacteria in the growing stage are transformed into the resting stage when the system is approaching stationary (Equation (4)). The transformation could be well described by a constant rate [18].

$$
\begin{gathered}
\frac{d S}{d t}=k_{\text {growth }} \times S-k_{\text {death }} \times S-k_{S R} \times S+k_{R S} \times R \\
\frac{d R}{d t}=k_{S R} \times S-k_{R S} \times R-k_{\text {death }} \times R
\end{gathered}
$$

where $S$ and $R$ are the bacterial number for the growing subpopulation and resting subpopulation, respectively, and $k_{S R}$ is a constant parameter that simulates the transfer from the growing stage into the resting stage.

\subsection{Antibacterial Effect Model}

The antibacterial effect can be modelled for either increasing the death rate or decreasing the growth rate, as shown in Figure 2. The antibacterial effect can be assumed to be non-linearly dependent on the antimicrobial concentration and is modelled by a sigmoid $E_{\text {max }}$ model (Equation (5)):

$$
\text { Effect }=\frac{E_{\max } \times C^{\gamma}}{E C_{50}^{\gamma}+C^{\gamma}}
$$

where $E_{\max }$ is the maximum effect on death rate, $E C_{50}$ represents the concentration of drug that produces half of $E_{\max }, \gamma$ is the coefficient, and $C$ is the antibacterial concentration.

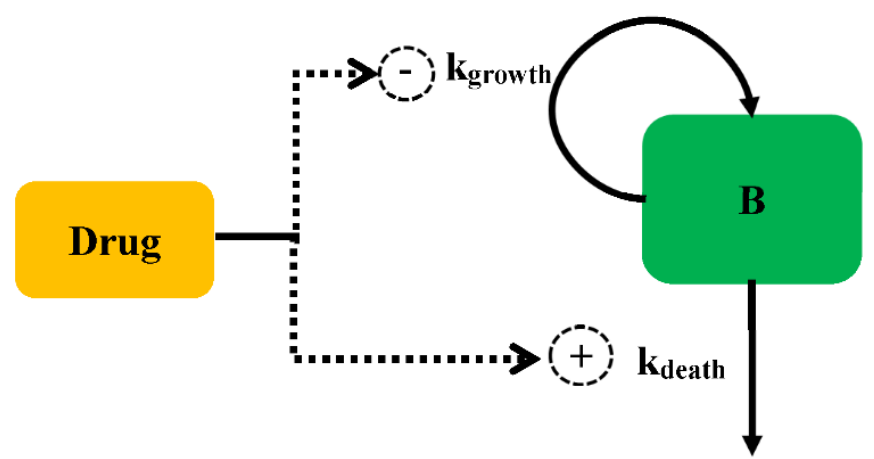

Figure 2. Schematic illustration of antibacterial effect against bacteria. 
However, if there is insufficient information to estimate $E_{\text {max }}$, the following power equation can be used to describe the antibacterial effect according to Equation (6):

$$
\text { Effect }=\text { Slope } \times C^{\gamma}
$$

Drug-resistant bacteria may occur during therapy and influence clinical perspective, with unrationed antibacterial use for many decades being the main reason leading to the selection for resistance [19]. The semi-mechanistic PK/PD model can describe the relationship between drug exposure and the emergence of resistance. In theory, by increasing $E C_{50}$ or decreasing $E_{\max }$, the resistance can be captured in the PK/PD model. If high drug concentrations can suppress the resistance, the increase in $E C_{50}$ is used in the model. By contrast, the decrease in $E_{\text {max }}$ is more suitable when the increasing dose cannot eliminate resistance [20].

\subsubsection{Persistent Resistance}

Bacteria can exhibit phenotype tolerance, whereby they can survive under antibacterial treatment without acquiring new mutations. Generally, a proliferating susceptible subpopulation always has a small fraction of non-proliferating subpopulations (persisters). In the absence of antimicrobial drugs, persisters can switch to the proliferating state, which can cause post-treatment relapses and enable the development of genetic resistance. Unlike genetic resistance, persistent resistance is non-inheritable, although the frequency of persisters in a population can be genetically determined [21].

The persisters were modelled according to the idea of a phenotypic switching between a normal growth subpopulation and a persistent subpopulation. Nilsen described two states of bacteria growing under antibiotics: one growing as a susceptible subpopulation and the other as a resting resistant subpopulation (Model 1, Figure 3) [18]. Different states are assumed to have the same death rate $\left(k_{\text {death }}\right)$. The antimicrobial drugs only influence the growing state. With a first-order constant $\left(k_{S R}\right)$, bacteria can transform from the growing state to the resting state. This model can explain the biphasic bacterial concentration-time curves, with a rapid killing rate followed by a decline in the killing rate over time.

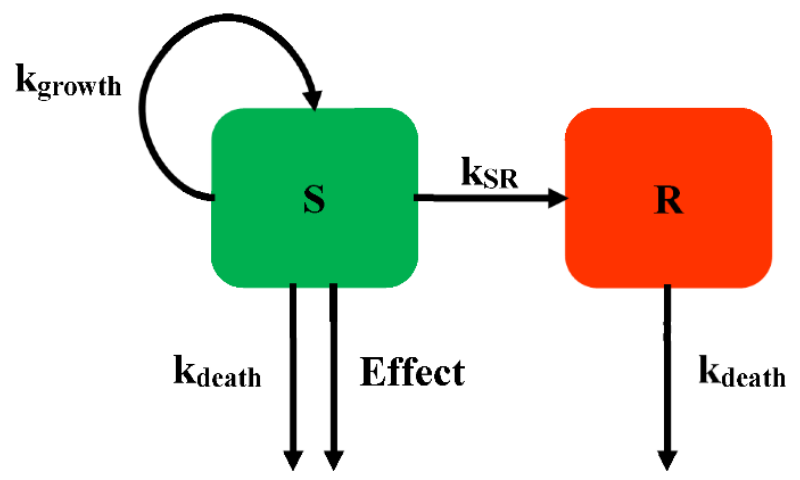

Figure 3. Schematic illustration of persistent resistance (Model 1).

For Model 1, the susceptible subpopulation is inhibited by antimicrobials in the growing state. The resting state, which is unsusceptible to antibacterial, is employed for the model describing the biphasic kill, which can always be found in time-killing curves. Nielsen successfully described the time-course of Streptococcus pyogenes exposed to five different antimicrobial drugs. In addition, the fine-tuning of this model structure allows further study in the application of the semi-mechanistic model.

Khan et al. further developed Model 2 (Figure 4) to describe the killing kinetics for Escherichia coli (E. coli) exposed to ciprofloxacin [22], with each subpopulation including three states for drug-susceptible growing bacteria $(S)$, resting non-growing bacteria $(R)$, and non-colony-forming drug-susceptible bacteria $(N c)$. The Nc subpopulation is rendered nongrowing under the influence of the drug and is unable to grow on agar plates. This Nc state 
is most likely due to the formation of filaments, which is well known when E. coli is exposed to ciprofloxacin. The adaption of the Nc state has significantly improved the description of the time-killing experiment [22]. If there is insufficient drug to kill the filament bacteria, they may revert to susceptible growing bacteria at constant rates $\left(k_{N c S}\right.$ or $\left.k_{S N c}\right)$. The bacteria in the $S$ and Nc states are both affected by the drug. The resting subpopulation is assumed to have a different $E C_{50}$ compared with the susceptible subpopulation. The kinetics of the bacteria with time for different compartments is described in Figure 4.

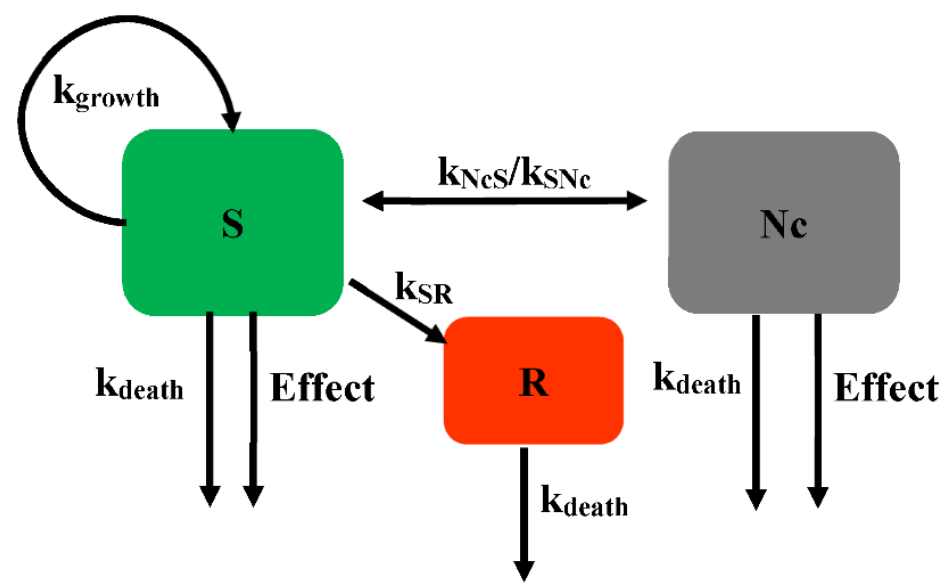

Figure 4. Schematic illustration of persistent resistance (Model 2).

The mathematical equation describing the bacterial count for the different subpopulations of Model 2 is shown in Equations (7)-(9).

$$
\begin{gathered}
\frac{d S}{d t}=k_{\text {growth }} \times S-k_{\text {death }} \times S-E f f e c t \times S-k_{S R} \times S-k_{S N c} \times S+k_{N c S} \times N c \\
\frac{d R}{d t}=k_{S R} \times S-k_{\text {death }} \times R \\
\frac{d N c}{d t}=k_{S N c} \times S-k_{N c S} \times N c-k_{\text {death }} \times N c-E f f e c t \times N c
\end{gathered}
$$

where the Nc subpopulation is assumed to be non-growing under the influence of drug and unable to grow on agar plates. The transformation rates between the susceptible growing subpopulation and the $N c$ subpopulation are $k_{S N_{c}}$ and $k_{N c S}$.

Biofilms are sessile communities of bacterial cells, enclosed in an exopolymer matrix and adherent abiotic surfaces. In developed countries, $65 \%$ of all infections are caused by biofilms [23]. Biofilm plays an important role in immune evasion and tolerance toward antimicrobial agents, leading to persistent and chronic infections. Sou et al. proposed a model incorporating a semi-mechanistic description of biofilm development to evaluate drug action on bacteria (Model 3, Figure 5), with bacteria in the planktonic state $(P)$, the biofilm state $(B)$, and the latent state $(L)$. The planktonic state represents the fast-growing bacteria. The planktonic state can transit into a biofilm state, in which the bacteria can readily transform into a non-growing latent state, which is tolerant to antibacterial. The planktonic and biofilm states are both susceptible to antibiotics [24]. 


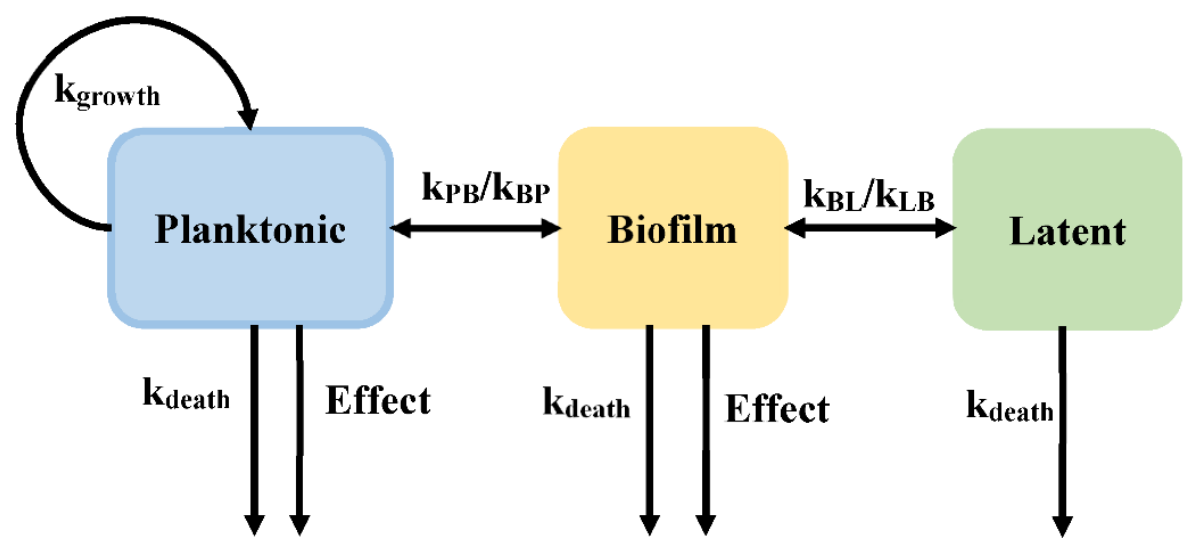

Figure 5. Schematic illustration of persistent resistance (Model 3).

Sou et al. assessed different equations that are suitable for use in the semi-mechanistic model describing the drug effect of Pseudomonas aeruginosa chronic lung infections. For example, different growth equations were outlined as exponential, capacity-limited, Gompertz, and logistic growth, as equation 9 shown. Using the Akachi information criterion (AIC) and goodness-of-fit between prediction and observation, the best equation (capacitylimited growth function) was selected to describe planktonic cell growth. In addition, they also evaluated the equation relating to the transport rate from the planktonic state to the biofilm state $\left(k_{P B}\right.$, as shown in the Equation (10)) and the antibacterial effect (Effect).

$$
\begin{gathered}
k_{P B}=k_{P B 0} \times \frac{P+B+L}{B_{\max }} \\
k_{P B}=k_{P B 0} \times t \\
k_{P B}=k_{P B 0} \times[1-\exp (-t)]
\end{gathered}
$$

where $P, B$, and $L$ represent the bacterial count in the planktonic state, biofilm state, and latent state, respectively. The transition rate $\left(k_{P B}\right)$ is assumed to have different functions: a first-order transition dependent on the amount of bacterial in the system or increasing with time in a linear or a non-linear manner.

Multistate tuberculosis (M. tuberculosis) exists in growing and dormant forms in a stationary-phase. In addition, both in vitro and in vivo, $M$. tuberculosis exists in a stage that is not able to form colonies on solid media, while being able to multiply in liquid media [25]. The PD model has been described as consisting of fast- $(F)$, slow- $(S)$, and non-multiplying $(N)$ bacterial states (Model 4, Figure 6) [26]. The mathematical equation was according to Equations (11)-(13). Except for the transformation from fast- to slow-multiplying states, bacteria can interconvert into each state with a first-order rate. The transfer rate from fast- to slow-multiplying bacteria $\left(k_{F S}\right)$ is estimated using a linear or non-linear manner dependent on time. The time courses of the bacterial count change are described in the following equations. They separate the drug effect on the inhibition of the growth of fast-multiplying states and the simulation of the death of slow-multiplying states. The $E_{\text {max }}$ and $E C_{50}$ are assumed to be different values for fast- and slow-multiplying states, and no death rate is described in the mechanistic PD model of M. tuberculosis.

$$
\begin{gathered}
\frac{d F}{d t}=k_{\text {growth } \times}\left(1-\text { Effect }_{F}\right) \times F+k_{S F} \times S+k_{N F} \times N-k_{F S} \times F-k_{F N} \times F \\
\frac{d S}{d t}=k_{F S} \times F+k_{N S} \times N-k_{S F} \times S-k_{S N} \times S-E f f e c t_{S} \times S \\
\frac{d N}{d t}=k_{F N} \times F+k_{S N} \times S-k_{N S} \times N-k_{N F} \times N
\end{gathered}
$$

where $k_{F S}, k_{S F}, k_{F N}, k_{N F}, k_{S N}$, and $k_{N S}$ are the transport rates among different subpopulations. $\mathrm{F}, \mathrm{S}$, and $\mathrm{N}$ are the bacterial numbers in the fast-, slow-, and non-multiplying subpopula- 
tions. Effect $F$ and Effect $t_{s}$ are the antibacterial effects on the fast-multiplying bacteria and slow-multiplying bacteria, respectively.

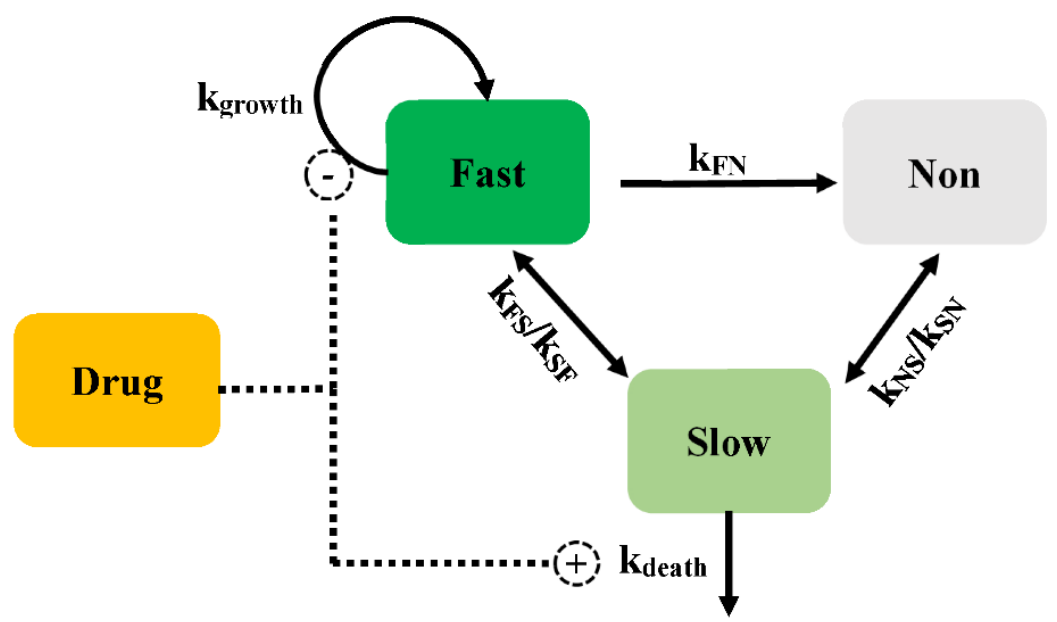

Figure 6. Schematic illustration of persistent resistance (Model 4).

\subsubsection{Pre-Existing Resistance}

Considering the mutant rate and initial inoculum, the bacterial system more likely presents a pre-existing subpopulation for high initial inoculum [27]. A longitudinal model consists of a susceptible subpopulation and a pre-existing resistant subpopulation (Model 5). In each subpopulation, the bacteria exist in two states: proliferating antibiotic susceptible bacteria and resting non-proliferating bacteria. Both are assumed to have the same growth rate, death rate, and maximum killing rate $\left(E_{\max }\right)$, but the two subpopulations differ in the values of $E C_{50}$. The drug concentration that produces $50 \%$ of $E_{\max }$ for the susceptible subpopulation is much smaller than for the resistant subpopulation. The bacterial count change for the susceptible and resistant subpopulations can be defined by the Equations (14) and (15). This model is also used to describe the dynamic kinetics of intestinal flora in vivo [28].

$$
\begin{gathered}
\frac{d S}{d t}=k_{\text {growth }} \times S-\frac{E_{\text {max }} \times C^{\gamma}}{E C_{50, S}+C^{\gamma}} \times S-k_{\text {death }} \times S \\
\frac{d R}{d t}=k_{\text {growth }} \times R-\frac{E_{\text {max }} \times C^{\gamma}}{E C_{50, R}+C^{\gamma}} \times R-k_{\text {death }} \times R
\end{gathered}
$$

where $E C_{50, s}$ and $E C_{50, R}$ represent the concentration of drug that produces half of $E_{\max }$ for the susceptible subpopulation and the resistant subpopulation, respectively.

There is a model that contains a susceptible subpopulation $(S)$, an intermediate subpopulation $(I)$, and a resistant subpopulation $(R)$, which is also considered to evaluate the time-courses of bacteria counts (Model 6, Figure 7).

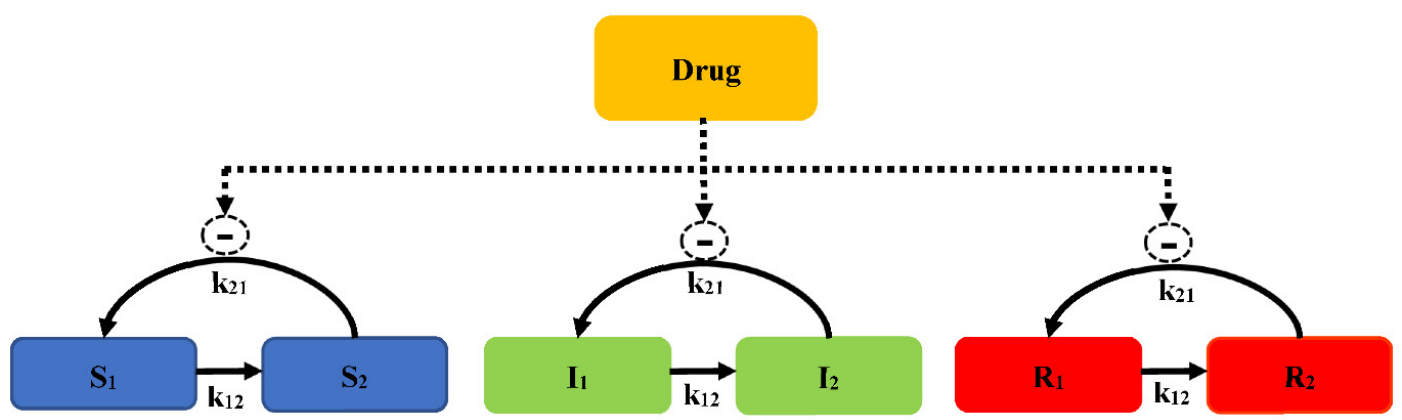

Figure 7. Schematic illustration of pre-existing resistance (Model 6). 
A life cycle growth model is used to describe the underlying biology of bacterial replication. The bacterial replication for each subpopulation is defined as two states: preparing for replication (state 1 ) and immediately before the replication step (state 2 ). The replication rate constant $\left(k_{21}\right)$ is assumed to evaluate different susceptibility subpopulations. The total concentration of viable bacteria $\left(C F U_{\text {all }}\right)$ is calculated as Equation (16):

$$
C F U_{\text {all }}=S_{1}+S_{2}+I_{1}+I_{2}+R_{1}+R_{2}
$$

The concentration of bacteria counts for the susceptibility subpopulation at state 1 is described as Equation (17):

$$
\frac{d S_{1}}{d t}=R E P \times(1-D r u g) \times k_{21} \times S_{2}-k_{12, S} \times S_{1}
$$

where $k_{21}$ is the replication rate constant, $k_{12}$ is the growth rate constant, and REP is the replication factor, which is calculated as Equation (18):

$$
R E P=2 \times\left(1-\frac{C F U_{\text {all }}}{C F U_{\text {all }}+C F U_{\text {max }}}\right)
$$

In the initial cultivation, REP represents a 100\% probability of successful replication. As $C F U_{\text {all }}$ approaches the maximum bacterial size $\left(C F U_{m a x}\right), R E P$ approaches a $50 \%$ successful replication, with the total viable count remaining constant. The antibacterial effect is described by the $E_{\max }$ model. The concentration of bacteria counts for the susceptibility subpopulation at state 2 is described as Equation (19):

$$
\frac{d S_{2}}{d t}=-k_{21} \times S_{2}+k_{12, S} \times S_{1}
$$

Similar equations are used for states 1 and 2 of the intermediate $\left(\mathrm{I}_{1}\right.$ and $\left.\mathrm{I}_{2}\right)$ and resistant subpopulations ( $\mathrm{R}_{1}$ and $\mathrm{R}_{2}$ ), but using different subpopulation parameters, such as $E_{\text {max }}, E C_{50}$, and $k_{12}$. To better characterize $E$. coli when exposed to ertapenem (a broadspectrum carbapenem), the model consists of the susceptible growing state $(S)$, intermediate non-growing state $(I)$, and resistant non-growing state $(R)$ for two co-existing bacterial subpopulations (a susceptible subpopulation and a resistant population). Bacteria in $S$ and $I$ are drug susceptible, and bacteria can transform between states. This model well describes the results of an in vitro PD study of three E. coli strains, a native strain, an ESBL-producing strain, and an ESBL-producing strain with reduced expression of porins OmpF and OmpC.

\subsubsection{Adaptive Resistance}

Adaptive resistance is a specific class of non-mutational resistance that is characterized by its transient nature [29]. This resistant type is unstable and can be a repetitive and reversible occurrence, leading to a moderate broad-spectrum drug resistance. Adaptive resistance might explain the phenomenon of "baseline creep", whereby the average MIC of a given medically important bacterial species increases steadily but inexorably over time. Tam et al. introduced an adaption factor $(\alpha)$ dependent on time and drug concentration by a saturable function of antimicrobial selective pressure, as shown in Equation (20) [30]:

$$
\alpha=1+\beta\left[1-e^{-e(t) \times t \times \tau}\right]
$$

where $\beta$ is the maximal adaption and $\tau$ is a rate constant of the adaption factor. An increase in adaptive factor can be implemented to result in a gradual increase in $E C_{50}$, which can be considered as an evolution of the initial bacteria toward a resistant subpopulation.

Jacobs et al. proposed a new adaption function based on an indirect model according to Equations (21) and (22) (Model 7) [5]. The time to adaptation is determined by the mean turnover time of adaptive resistance and is thus independent of drug concentrations. This 
adaptive function can reflect the situation that bacteria need to synthesize a protein to express a resistance mechanism, such as the expression of an efflux pump.

$$
\begin{gathered}
\frac{d(\text { Adaption })}{d t}=\left(\frac{S_{\text {max }}-C}{S C_{50}+C}-\text { Adaption }\right) \times k_{\text {out }} \\
E C_{50}=E C_{50, \text { base }} \times(1+\text { Adaption })
\end{gathered}
$$

where $E C_{50, \text { base }}$ is the antibacterial concentration causing $50 \%$ of $E_{\max }$ in the absence of adaption, $S_{\max }$ is the maximum fold-increase in $E C_{50}$ due to adaptive resistance, $S C_{50}$ is the concentration causing $50 \%$ of $S_{\max }$, and $k_{\text {out }}$ is the first-order rate constant for adaption. The adaption changes the extent of $E C_{50}$ in response to the alteration of susceptibility for each subpopulation.

The adaptive resistance of aminoglycosides is a PD reversible process, which indicates that bacteria can revert to the initial state (susceptible to the antimicrobial drug) when drug exposure diminishes. Mechanistically, the expression of MexXY, an efflux pump related to the export of aminoglycosides, is turned down as drug exposure gradually diminishes, leading to susceptibility. Mohammad [31] introduced the development of adaptive resistance as a binding function, as Equations (23)-(25) shown, where the degree of binding resulted in a reduction of $E_{\max }$ from the initial value (Model 8, Figure 8).

$$
\begin{gathered}
\frac{d A R_{O F F}}{d t}=k_{o f f} \times A R_{O N}-k_{o n} \times A R_{O F F} \times C \\
\frac{d A R_{O N}}{d t}=k_{o n} \times A R_{O F F} * C-k_{o f f} \times A R_{O N} \\
E_{\text {max }}=E_{\text {max }, \text { base }} \times\left[1-\frac{A R_{o n}}{A R_{O N}+A R_{50}}\right]
\end{gathered}
$$

where $A R_{O N}$ describes the degree of adaptive resistance in the "on" state, $A R_{O F F}$ represents the adaptive resistance in the "off" state, $A R_{50}$ is the value of $A R_{O N}$ when $E_{\max }$ is reduced by $50 \%$, and $k_{o n}$ and $k_{\text {off }}$ are the constants of the reversal rate of adaptive resistance. Initially, $A R_{O N}$ is empty, and the whole fraction of a hypothetical amount is in $A R_{O F F}$; upon drug exposure, the amount transfers into $A R_{O N}$, with a rate constant $k_{o n}$. With a reduction of the antimicrobial, the bacteria gradually revert into the initial state $\left(A R_{O F F}\right)$ with $k_{\text {off. }}$.

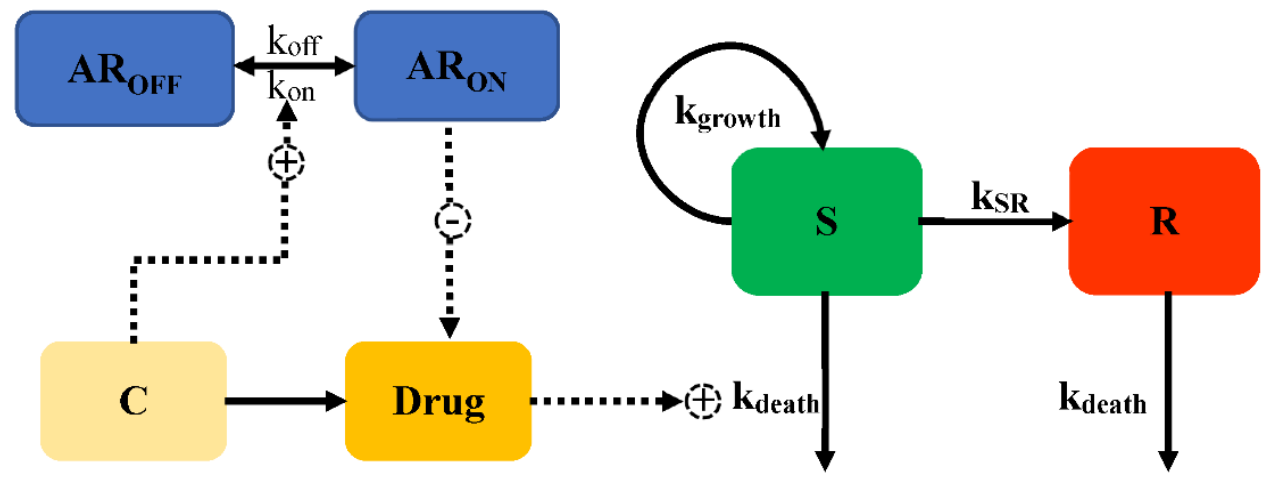

Figure 8. Schematic illustration of adaptive resistance (Model 8).

\section{Methods for the Development of Semi-Mechanism PK/PD Model}

To develop an efficient semi-mechanistic PK/PD model, strain selection, in vitro timekilling experiments, and the establishment of a model need to be performed. Some details are listed below.

Strain selection: One reference strain, and one susceptible and one less-susceptible clinical isolate are required. The selection of a reference strain can demonstrate reproducibility. It is better to choose virulent clinical isolates that can support translation to animals. Prior 
to establishing the model, the MIC needs to be determined, following the guidance, and the mutant frequency needs to be evaluated, which can assist with model establishment [27].

In vitro time-killing curves: Bacterial counts should be monitored repeatedly under multiple drug concentrations at different timepoints, including the susceptible subpopulation and the resistant subpopulation, in the in vitro time-killing experiment.

Establishing a model: Combined with the results of the in vitro experiment, a model, introduced as above, is selected. It is better to evaluate parameters and mathematical form, applying a non-linear mixed effects (NLME) model to run the semi-mechanistic PD model. Model performance is assessed by the evaluation of diagnostic plots, model fit, and the plausibility of estimated parameter values. In addition, the difference in objective function value (OFV) is employed: when the reduction in OFV is at least 10.84, the alteration is positive. AIC and Bayesian information criterion (BIC) can provide a reference to select an optimum model. In addition, some diagnostic graphs, such as goodness-of-fit and visual predictive curves (VPC), can assist in determining the model [32].

\section{The Factors Affecting Model Establishment}

In the PD experiment, some factors affect the establishment of the model, such as the inoculum effect, host response, and different types of PD data. Integrating with these factors, a dosage regimen can be derived comprehensively. This section discusses how the semi-mechanistic PD model integrates with these factors to capture the kinetics of bacterial count under drug exposure.

\subsection{Inoculum Effect}

The inoculum effect is the phenomenon involving the attenuation of an antibacterial at a higher bacterial density of initial inoculum [17]. Numerous mechanisms have explained this PD phenomenon, which decreases the antibacterial effect: (1) due to the number of bacteria increasing, the concentration of antimicrobials is relatively decreased [17]; (2) during a high-density inoculum, a biofilm is established to hamper the antibacterial effect [18]; (3) in some cases, a high bacterial inoculum can mediate the expression of proteins that decrease antibiotic susceptibility, such as resistance enzymes or efflux pumps [19]; (4) higher concentrations of bacteria can increase the subpopulation of the pre-existing resistant subpopulation, while also enhancing the chances of a population spontaneously acquiring a mutation decreasing antibiotic susceptibility. A PK/PD model that can well capture this phenomenon would have an active effect on the selection of the dosage regimens.

Colistin is increasingly utilized to treat infections due to multidrug-resistance gramnegative pathogens, including $P$. aeruginosa, which greatly threatens human health. After displacing $\mathrm{Mg}^{2+}$ and $\mathrm{Ca}^{2+}$ from lipopolysaccharide binding sites, colistin disrupts the outer and cytoplasmic membranes. A model assessing the effect of $\mathrm{Mg}^{2+}$ and $\mathrm{Ca}^{2+}$ on the killing of P. aeruginosa by colistin was introduced by Bulitta et al. [33]. This model has also been successful in describing the inoculum effect. There are three different susceptibility subpopulations to colistin. To characterize the inoculum effect, all viable bacteria are assumed to synthesize and release freely diffusible signal molecules that can inhibit the killing effect.

To evaluate the inoculum effect and the lag time of the killing, a mathematical model of Ceftazidime against $P$. aeruginosa was developed, involving two different subpopulations integrated with different growth states, as shown in Model 7. Compared with different PD models, a model that captures the life cycle of bacterial replication and autolysin activity can well describe the in vitro time-killing curves. Ceftazidime is assumed to bind with penicillin-binding proteins (PBPs) $\left(\right.$ Stim $\left._{\text {Drug, } S}\right)$, which stimulate the autolysin effect $\left(A L y s_{S}\right)$, and the turnover of the autolysin effect causes the lag time of the killing. 
Autolysin activity is assumed to decrease the probability of successful replication, as shown in Equations (26) and (27):

$$
\begin{gathered}
\frac{d A L y s_{S}}{d t}=\left[\text { Stim }_{\text {Drug }, \mathrm{s}}-\left(1+\frac{S_{\text {max }, \text { loss }} \times C_{\text {sig } 1}}{C_{50, \text { Sig }}+C_{\text {sig } 1}}\right) \times A L y s_{S}\right] \times k_{\text {out }} \\
\text { Stim }_{\text {Drug }, S}=\frac{S_{\text {max }, S} \times C_{B}}{S C_{50}+C_{B}}
\end{gathered}
$$

where $S_{\max , S}$ is the maximum value of $A L y s_{S}$ (when $S_{\max , S}=1$, it indicates that the inoculum effect can completely inhibit replication at high drug concentrations), $S C_{50}$ is the drug concentration at which the input of autolysin effect is half of the maximally stimulated, $S_{\text {max,loss }}$ describes the maximum extent of the inoculum effect at high signal molecule concentrations, and $C_{50 \text {,sig }}$ is the signal molecule that can perform half of the maximum extent of the inoculum effect.

\subsection{Host Response}

For Gram-negative bacteria, the release of inflammatory products, such as LPS/endotoxin, may increase due to the administration of antimicrobial drugs. This can be characterized as a simulator of the innate immune response. Beta-lactams bind with PBP-1 or PBP-3 (penicillin-binding proteins), which may lead to the release of a large amount of endotoxin upon final bacterial lysis. With the description of the mathematical method, Thorste et al. explored the endotoxin release in the context of drug administration or bacterial growth, by the quantitative link of two processes of bacterial growth [34]. Quantifying the release of endotoxin would assist in the design of a valuable dosage regimen. The bacterial growth model is described as Model 2, and the modelling of endotoxin release consists of (i) binary fission (growth [G]), (ii) antibiotic-induced killing $(K)$, and (iii) natural bacterial death $(D)$ as Equations (28)-(30) shown.

$$
\begin{gathered}
\frac{d G}{d t}=k_{G, E T X} \times k_{\text {growth }} \times S-k_{e l} \times G \\
\frac{d K}{d t}=k_{K, E T X} \times\left(\frac{E_{\text {max }} \times C_{A B}^{\gamma}}{E C_{50}^{\gamma}+C_{A B}^{\gamma}}\right) \times S-k_{e l} \times K \\
\frac{d D}{d t}=k_{D, E T X} \times k_{\text {death }} \times(S+R)-k_{e l} \times D
\end{gathered}
$$

where $k_{G, E T X}, k_{K, E T X}$, and $k_{D, E T X}$ are assumed to be constant for different bacterial subpopulation release endotoxin, and $k_{e l}$ represents the elimination rate, which is set to zero in the static model. For the in vitro dynamic model, a Gaussian function is employed to describe the transition from a susceptible state to a filamentous state $\left(k_{\text {filament }}\right)$ according to Equation (31).

$$
k_{\text {filament }}=e^{-\frac{\left(C_{A B}-\theta_{M I C, F} \times M I C\right)^{2}}{2}}
$$

where $\theta_{M I C, F}$ represents being centered around an antibiotic concentration given by the pathogen MIC times an estimated parameter.

$$
\begin{gathered}
\frac{d F}{d t}=-\left(\frac{E_{\text {max }} \times C_{A B}^{\gamma}}{E C_{50}^{\gamma}+C_{A B}^{\gamma}}\right) \times F-k_{\text {death }} \times F+k_{\text {filament }} \times S+k_{\text {growth }} \times F \\
\frac{d F K}{d t}=k_{F, E T X} \times\left(\frac{E_{\text {max }} \times C_{A B}^{\gamma}}{E C_{50}^{\gamma}+C_{A B}^{\gamma}}\right) \times F-k_{\text {el,ETX }} \times F K
\end{gathered}
$$

where Equation (32) describes the formation of filaments. $k_{\text {growth }}$, differentiated from the above, represents an increase in biomass, which leads to increased endotoxin release upon 
the antibiotic-induced killing of the filaments. Equation (33) described the antibioticinduced killing of filaments.

It is difficult to directly describe the host response impact on enhancing the antibacterial effect or death rates of the bacteria. A biomarker is defined as a quantifiable biological parameter to guide diagnosis, the initiation, monitoring and cessation of therapy, and for prediction of clinical outcomes [35]. Different biomarkers were incorporated into the PK/PD model to quantify the immune system effect. Neutrophils and cytokines (TNF$\alpha$ ) [36] were selected as the biomarker to illustrate the effect of an immune cell on bacteria. An alternative method is to quantify the number of immune cells, with the host response assumed to be dependent on both the cell counts and bacterial counts, as shown in the Equation (34), which describes the time course of bacteria without drug exposure.

$$
\frac{d B}{d t}=k_{n e t} \times \frac{B_{\max }-B}{B_{\max }} \times B-\left(\frac{k_{i r} \times A N C}{A N C_{50}+A N C}\right) \times B
$$

where $A N C$ is the absolute neutrophil count, $A N C_{50}$ is the ANC required to achieve $50 \%$ of the maximal kill rate, and $k_{i r}$ describes the maximum rate at which neutrophils can kill the pathogens.

The short- and long-term infection dynamics of TB are believed to be strongly influenced by the immune system response of an affected patient. A model designed with the mechanism of the immune system response to infection with $M$. tuberculosis was introduced by John et al. [37], which can be assumed in terms of the interaction between bacteria, immune cells in the alveoli of the lung, and the lymph nodes.

Comprehending the mechanism and mathematically quantifying the time-course of the host, it is helpful to determine an optimal dosage for the patient [38].

\subsection{The Types of Pharmacodynamic Data for the Model}

Initially, a semi-mechanistic PK/PD model was developed by the static time-killing curves, which only possess two variables: concentration and time. It is more suitably characterized by the mechanistic model than by MIC, with only one variable, concentration. Nielsen adapted Model 1 to successfully describe the kinetics of Streptococcus pyogenes exposure to five antibiotics [18]. However, due to the limitation of nutrients, the static time-killing curves are only represented within a $24 \mathrm{~h}$ period, and it lacks the ability to capture the resistance. To simulate in vivo conditions, where the drug is disposed and gradually changed, the dynamic model that can simulate the time-course of antibacterial concentrations observed in patients is used to establish the mechanistic PK/PD model. By adjusting pumps, the nutrients and toxic metabolites can be updated in the model, and a long-term culture can then be performed. The hollow fiber infectious model and the in vivo murine infection model were used to validated the predicted results by the semi-mechanistic PK/PD model, respectively, and revealed that the model can correctly predict the similar bacterial response (bacterial count change after $24 \mathrm{~h}$ exposure) in both in vitro and in vivo conditions [39].

It is a question of which types of data, static or dynamic time-killing curves, should be adapted to develop the semi-mechanistic PK/PD model. Comparing static or dynamic time-killing curves to support the precise parameter estimations of a PK/PD model, a study revealed that different settings between static and dynamic experiments did not significantly affect the growth kinetics of the bacteria [40]. Jacobs et al. distinguished six models with different mechanisms by static or dynamic time-killing curves. Dynamic conditions provided an accurate estimation for some parameters, and static conditions yielded more precise estimations.

Furthermore, more studies employ static data to establish the mechanistic model and use dynamic data to validate the model [5]. To optimize the combined dosage regimens of meropenem-tobramycin against $P$. aeruginosa, a mechanistic model consisting of three different subpopulations is used to derive the dosage regimens [41]. Static time-killing curves are performed to characterize the effect of different meropenem and tobramycin 
doses, respectively, and an accurate hollow fiber infectious model is used to evaluate and validate the dosage regimen. According to the results, the in silico simulation of the antibacterial effect against $P$. aeruginosa and the suppression of resistance are similar to the results of the hollow fiber infectious model.

\section{Application of Model in Dosing Regimen, Combination Therapy, and Determination of Breakpoint}

With mathematical equations, the semi-mechanistic model can capture the time course of bacterial growth to evaluate the efficacy of the dose. The semi-mechanistic PK/PD model is widely applied for drug research and development. As shown in Table 1, we investigated the recent articles that adapt the semi-mechanistic PK/PD model. This model is an essential part of evaluating the efficacy of a preclinical drug and raising the rational of "old medicine". Due to the complexity of drug resistance, more models employ various resistance mechanisms to describe the PD data. The semi-mechanistic PK/PD model was applied in the determination of dosage regimens, guidance of combination therapy, determination of the MIC-related breakpoint, and prediction of the kinetics of bacteria in the gut. This section introduces the application.

Table 1. The semi-mechanistic PK/PD of antibacterial against different bacterial populations.

\begin{tabular}{|c|c|c|c|c|}
\hline Antimicrobial Class & Drug & Bacteria & Resistant Species & References \\
\hline \multirow[t]{6}{*}{ Aminoglycosides } & \multirow[t]{4}{*}{ Gentamicin } & \multirow{2}{*}{$\begin{array}{l}\text { Staphylococcus aureus } \\
\text { Pseudomonas aeruginosa } \\
\text { Acinetobacter baumannii }\end{array}$} & Adaptive resistance & [42] \\
\hline & & & Adaptive resistance & {$[43]$} \\
\hline & & Escherichia coli & $\begin{array}{l}\text { Adaptive resistance } \\
\text { Persistent resistance }\end{array}$ & [31] \\
\hline & & Pseudomonas aeruginosa & Pre-existing resistance & [44] \\
\hline & \multirow[t]{2}{*}{ Tobramycin } & \multirow{2}{*}{ Pseudomonas aeruginosa } & Persistent resistance & [24] \\
\hline & & & Pre-existing resistance & [45] \\
\hline \multirow[t]{7}{*}{ Beta-lactams } & \multirow[t]{2}{*}{$\begin{array}{l}\text { Benzylpenicillin } \\
\text { Cefuroxime }\end{array}$} & \multirow[t]{2}{*}{ Streptococcus pyogenes } & Persistent resistance & [18] \\
\hline & & & Adaptive resistance & [30] \\
\hline & \multirow[t]{2}{*}{ Meropenem } & \multirow[t]{2}{*}{ Pseudomonas aeruginosa } & $\begin{array}{l}\text { Pre-existing resistance } \\
\text { Persistent resistance }\end{array}$ & [46] \\
\hline & & & $\begin{array}{l}\text { Pre-existing resistance } \\
\text { Persistent resistance } \\
\text { Adaptive resistance }\end{array}$ & [47] \\
\hline & Ertapenem & Escherichia coli & $\begin{array}{l}\text { Pre-existing resistance } \\
\text { Persistent resistance }\end{array}$ & [48] \\
\hline & Ceftobiprole & Staphylococcus aureus & Persistent resistance & [49] \\
\hline & Cefuroxime & Escherichia coli & Persistent resistance & [34] \\
\hline \multirow[t]{6}{*}{ Fluoroquinolones } & \multirow[t]{2}{*}{ Moxifloxacin } & Streptococcus pyogenes & Persistent resistance & [18] \\
\hline & & Staphylococcus aureus & $\begin{array}{l}\text { Pre-existing resistance } \\
\text { Adaptive resistance }\end{array}$ & [50] \\
\hline & \multirow[t]{3}{*}{ Ciprofloxacin } & Staphylococcus aureus & Pre-existing resistance & [51] \\
\hline & & Pseudomonas aerugeinosa & Adaptive resistance & [52] \\
\hline & & Escherichia coli & $\begin{array}{l}\text { Pre-existing resistance } \\
\text { Persistent resistance }\end{array}$ & [22] \\
\hline & Enrofloxacin & Escherichia coli & Pre-existing resistance & [28] \\
\hline Macrolides & Erythromycin & Streptococcus pyogenes & Persistent resistance & [18] \\
\hline \multirow[t]{2}{*}{ Polymyxin } & \multirow[t]{2}{*}{ Colistin } & \multirow[t]{2}{*}{ Pseudomonas aeruginosa } & $\begin{array}{l}\text { Adaptive resistance } \\
\text { Persistent resistance }\end{array}$ & [53] \\
\hline & & & Pre-existing resistance & [54] \\
\hline Chloramphenicols & Florfenicol & $\begin{array}{l}\text { Pasteurella multocida } \\
\text { Mannheimia haemolytica }\end{array}$ & Persistent resistance & [55] \\
\hline Tetracyclines & Eravacycline & $\begin{array}{c}\text { Escherichia coli } \\
\text { Acinetobacter baumannii }\end{array}$ & Adaptive resistance & [56] \\
\hline
\end{tabular}




\subsection{Dosage Regimen}

Muhammad et al. adapted a whole-PBPK model combined with Model 2 to establish a PBPK/PD model of ciprofloxacin against E. coli [57]. This model can predict different time courses of bacterial killing in the extracellular fluid of different tissues. The results indicated the most antibacterial efficiency in the lung and kidney, which corresponds well to ciprofloxacin's indications of pneumonia and urinary tract infections [57]. Sy et al. established a PK/PD model by the PBPK model and PD model (Model 2) to derive the best PD index $\left(f \mathrm{~T}>\mathrm{C}_{\mathrm{T}}\right)$ of avibactam against $P$. aeruginosa in combination with ceftazidime. Setting a threshold avibactam concentration of $1 \mathrm{mg} / \mathrm{L}$, for the most ceftazidime-resistant strain, at least $500 \mathrm{mg} \mathrm{q} 8 \mathrm{~h}$ avibactam as a $2 \mathrm{~h}$ infusion can achieve at least a 2-log kill [58]. Kuepfer et al. described developing a PBPK/PD model for ciprofloxacin against E. coli in which the PD model allows the microbial growth to be quantified in the absence, as well as in the presence of ciprofloxacin-mediated inhibition. By comparing the PK profiles of concentrations in the lung and serum, $500 \mathrm{mg}$ b.i.d. dosage regimen was already high enough to promote bacterial killing [59].

Lin et al. established a population PK model of a two-compartment model with linear elimination, assumed as plasma compartments and ELF (epithelial lining fluid) compartments. Model 5, established with the in vivo time-killing curves of the mouse lung infection model, was integrated with a population PK model to assess the efficacy of different dosage regimens of aerosolized colistin against $P$. aeruginosa. Deterministic simulations suggested that an inhalational dose of $60 \mathrm{mg}$ colistin base activity every $12 \mathrm{~h}$ may be required to achieve $\geq 2 \log 10$ killings at $24 \mathrm{~h}$ after the commencement of inhaled therapy [54].

\subsection{Combination Therapy}

Semi-mechanistic PK/PD models that are developed based on in vitro single and combination experiments can be valuable for proposing a dosage regimen for drug combinations. Typically, antibiotic combinations are assessed to overcome or suppress the emergence of resistance and/or to increase efficacy.

Zhao et al. [60] established a PK/PD model to quantify the interaction between polymyxin B (PMB) and minocycline (MIN) against multidrug-resistant Klebsiella pneumoniae. The description of the resistant state is an adapted Model 8. In addition, a basic additive interaction model was used in the selection of combination time-kill experiments of interest as Equation (35) described:

$$
k_{\text {drug.COMB }}=k_{\text {drug.MIN }} \times \operatorname{Inh}_{A R . M I N}+k_{\text {drug.PMB }} \times \operatorname{Inh}_{A R . P M B}
$$

where $k_{d r u g, C O M B}$ is the combined drug effect; $k_{d r u g, M I N}$ and $k_{d r u g, P M B}$ are the $k_{d r u g}$ of MIN and PMB, respectively; and $I n h_{A R, M I N}$ and $I n h_{A R, P M B}$ are the $I n h_{A R}$ of MIN and PMB, respectively.

Aranzana-Climent et al. [61] also employed Model 8 as the PD sub-model to describe the resistant mechanism. The drug interaction sub-model is described as Equation (36), as PD parameters are influenced by the presence of the other drug:

$$
E C_{50, M I N}=E C_{50, M I N \text { alone }} \times\left(1+\frac{I N T P_{P M B} \times[P M B]}{E C_{50, I N T-P M B}+[P M B]}\right)
$$

where $E C_{50, M I N}$ is the final $E C_{50}$, which was influenced by polymyxin $B$; $E C_{50, M I N}$ alone $(\mathrm{mg} / \mathrm{L})$ is the $E C_{50}$ of minocycline, $I N T_{P M B}$ (no unit) is an interaction factor, and $E C_{50, I N T-P M B}(\mathrm{mg} / \mathrm{L})$ is the polymyxin B concentration needed to reach $50 \%$ of the interaction effect.

In addition, Brill et al. [62] overviewed the semi-mechanistic models to characterize the combined effect and outlined steps to establish models. Thirteen publications were reported about the combination mechanisms such as subpopulation synergy, different effect sites, and interaction functions. Subpopulation synergy was applied in several models, and 
independent kill rates of each drug were typically added using various types of interaction functions [62]. As the semi-mechanistic PK/PD model established, the evaluation of recommended dosing regimens and determination of an optimized dosage were performed. To expedite the application of semi-mechanistic PK/PD model, they uploaded the information for public availability of these models on DDMORE repository [63].

\subsection{PK/PD Breakpoint and Cutoffs}

The breakpoint or PK/PD cutoff can be determined by the semi-mechanistic PK/PD model. The MIC can be computed as a secondary parameter according to Equation (37).

$$
M I C=E C_{50} \times\left(\frac{k_{\text {growth }}-0.29}{E_{\text {max }}-\left(k_{\text {growth }}-0.29\right)}\right)^{\frac{1}{\text { Gama }}}
$$

Pelligand et al. applied Model 1 to derive the PK/PD breakpoint of florfenicol against Pasteurella multocida and Mannheimia haemolytica with in vitro time-killing curves of different inoculum sizes. For both bacteria, the $f$ AUC/MIC is selected as the PK/PD index in predicting bacterial killing with different MIC values. In silico simulation showed that average free plasma concentrations equal 1.2-1.4 times the respective MIC can perform with the maximum efficacy [55].

Iqbal determined MIC-developed breakpoints for the killing and suppression of resistance development in plasma and tissue sites, skin, and muscle. The clinical microdialysis data and in vitro time-killing curves of moxifloxacin against $S$. aureus and $E$. coli were used to establish the PK/PD model, and the different MIC-breakpoints of different antibacterial effects in different tissues were established for both bacterial species [50].

\subsection{Prediction the Kinetic of Bacterial in Guts}

The semi-mechanistic PK/PD model can present the dynamics of bacterial ecology and resistance in the gut intestine tract. The transmission dynamics of the resistance genes are commonly categorized into vertical vs. horizontal. In addition, many models were established to predict the susceptibility change of bacteria under antibiotic exposure in the gut. Erwin et al. used Model 5 to describe the growth of different bacterial subpopulations and investigated the susceptibility change of E. coli above and below the epidemiological cutoff in steers. They concluded that $E$. coli susceptibility is a strong indicator of how steers respond to antimicrobial drug treatment [28]. The semi-mechanistic PK/PD model can assist in predicting the number of resistant enterobacteria excreted. Nguyen et al. also used Model 5 to capture the complex relationships between dosage regimen, antibiotic fecal concentrations, loss of susceptible enterobacteria, and growth of resistant strains in the feces of piglets receiving different doses of ciprofloxacin for 5 days. For the clinically relevant dose of $15 \mathrm{mg} / \mathrm{kg} /$ day for 5 days, the total amount of resistant enterobacteria excreted was predicted to be reduced by $75 \%$ and $98 \%$ when reducing the treatment duration to 3 days and 1 day, respectively [64]. The modelling of the growth dynamics of multiple E. coli strains after ampicillin treatment have also been established by Ahamad et al., who revealed that the short period and dosing frequency do not influence the growth of resistant E. coli [65].

\section{Overlook}

The PK/PD model of antibacterial is an accepted method for optimizing the dosage regimen and provide some assistance in drug development and research. Accumulating studies focus on the semi-mechanistic model to design regimens and explore the resistant mechanisms. In addition, the semi-mechanistic PK/PD model can provide foresight in the pharmacological field, and a more rational and safer dose can be derived by the semimechanistic model for use in clinical phase I and II experiments. 
However, from a broader view in terms of future direction in this field, some thoughts need to be focused

1. Regulation. The official regulations need to be published, which will play the role of encouragement and guidance.

2. Education. It is very important to tell the modelers how to establish a model and judge the model. It is an efficient way to acquire the relevant knowledge from the tutorial. Rowland et al. summarized the inception, maturation, and future vision about Pharmacometrics and Systems Pharmacology. Twenty representative particles over the past 10 years were outlined [66]. Besides the tutorials, the software company and the public training courses also can offer some guidance. For example, many detailed courses can be found on the Metrum research group (www.metrumrg.com (accessed on 6 January 2022)).

3. Share. It is critical and necessary to publish the model code for the subsequent model applications. This will help modelers to learn the programming languages. Of course, the excellent forms of programming languages are also important. Mathematical models are widely used in various fields that would require more competent modelers.

In conclusion, we summarized the establishment of semi-mechanistic PK/PD models that can describe different antibacterial resistant mechanisms. The mathematical equation can describe the bacterial count change under drug exposure. With the development of computer technology, in silico simulation and prediction can extensively apply in the pharmacological field. Presumably, it offers another aspect to alleviate and avoid the emergence of drug resistance.

Author Contributions: Writing—original draft preparation, K.M., K.Z., L.S. and Y.H.; writingreview and editing, W.M., X.X., M.H., Z.L. and L.H.; project administration, L.H. All authors have read and agreed to the published version of the manuscript.

Funding: This article was supported by the National key research and development program (2016YFD0501310).

Institutional Review Board Statement: Not applicable.

Informed Consent Statement: Not applicable.

Data Availability Statement: Not applicable.

Conflicts of Interest: The authors declare that the research was conducted in the absence of any commercial or financial relationships that could be construed as a potential conflict of interest.

\section{References}

1. Innes, G.K.; Randad, P.R.; Korinek, A.; Davis, M.F.; Price, L.B.; So, A.D.; Heaney, C.D. External Societal Costs of Antimicrobial Resistance in Humans Attributable to Antimicrobial Use in Livestock. Annu. Rev. Public Health 2020, 41, 141-157. [CrossRef]

2. CDC (Centers for Disease Control and Prevention); US DHHS (Department of Health and Human Services). 2013 Antibiotic Resistance Threats in the United States; CDC: Atlanta, GA, USA; US DHHS: Washington, DC, USA, 2013.

3. Mouton, J.W.; Ambrose, P.G.; Canton, R.; Drusano, G.L.; Harbarth, S.; MacGowan, A.; Theuretzbacher, U.; Turnidge, J. Conserving antibiotics for the future: New ways to use old and new drugs from a pharmacokinetic and pharmacodynamic perspective. Drug Resist. Updates 2011, 14, 107-117. [CrossRef]

4. Tängdén, T.; Ramos Martín, V.; Felton, T.W.; Nielsen, E.I.; Marchand, S.; Brüggemann, R.J.; Bulitta, J.B.; Bassetti, M.; Theuretzbacher, U.; Tsuji, B.T.; et al. The role of infection models and PK/PD modelling for optimising care of critically ill patients with severe infections. Intensive Care Med. 2017, 43, 1021-1032. [CrossRef] [PubMed]

5. Jacobs, M.; Grégoire, N.; Couet, W.; Bulitta, J.B. Distinguishing Antimicrobial Models with Different Resistance Mechanisms via Population Pharmacodynamic Modeling. PLoS Comput. Biol. 2016, 12, e1004782. [CrossRef]

6. Nielsen, E.I.; Friberg, L.E. Pharmacokinetic-pharmacodynamic modeling of antibacterial drugs. Pharmacol. Rev. 2013, 65, 1053-1090. [CrossRef]

7. Lees, P.; Pelligand, L.; Illambas, J.; Potter, T.; Lacroix, M.; Rycroft, A.; Toutain, P.L. Pharmacokinetic/pharmacodynamic integration and modelling of amoxicillin for the calf pathogens Mannheimia haemolytica and Pasteurella multocida. J. Vet. Pharmacol. Ther. 2015, 38, 457-470. [CrossRef]

8. Nielsen, E.I.; Cars, O.; Friberg, L.E. Pharmacokinetic/pharmacodynamic (PK/PD) indices of antibiotics predicted by a semimechanistic PKPD model: A step toward model-based dose optimization. Antimicrob. Agents Chemother. 2011, 55, 4619-4630. [CrossRef] 
9. Rathi, C.; Lee, R.E.; Meibohm, B. Translational PK/PD of anti-infective therapeutics. Drug Discov. Today. Technol. 2016, 21-22, 41-49. [CrossRef] [PubMed]

10. Wang, Y.; Zhu, H.; Madabushi, R.; Liu, Q.; Huang, S.M.; Zineh, I. Model-Informed Drug Development: Current US Regulatory Practice and Future Considerations. Clin. Pharmacol. Ther. 2019, 105, 899-911. [CrossRef]

11. Kristoffersson, A. Study Design and Dose Regimen Evaluation of Antibiotics Based on Pharmacokinetic and Pharmacodynamic Modelling. Doctoral Dissertation, Acta Universitatis Upsaliensis, Uppsala, Sweden, 2015.

12. Fan, J.; de Lannoy, I.A. Pharmacokinetics. Biochem. Pharmacol. 2014, 87, 93-120. [CrossRef] [PubMed]

13. Tan, Y.-M.; Chan, M.; Chukwudebe, A.; Domoradzki, J.; Fisher, J.; Hack, C.E.; Hinderliter, P.; Hirasawa, K.; Leonard, J.; Lumen, A.; et al. PBPK model reporting template for chemical risk assessment applications. Regul. Toxicol. Pharmacol. RTP 2020, 115, 104691. [CrossRef] [PubMed]

14. Kiang, T.K.; Sherwin, C.M.; Spigarelli, M.G.; Ensom, M.H. Fundamentals of population pharmacokinetic modelling: Modelling and software. Clin. Pharmacokinet. 2012, 51, 515-525. [CrossRef] [PubMed]

15. Jusko, W.J. Pharmacodynamics of chemotherapeutic effects: Dose-time-response relationships for phase-nonspecific agents. J. Pharm. Sci. 1971, 60, 892-895. [CrossRef] [PubMed]

16. Meagher, A.K.; Forrest, A.; Dalhoff, A.; Stass, H.; Schentag, J.J. Novel pharmacokinetic-pharmacodynamic model for prediction of outcomes with an extended-release formulation of ciprofloxacin. Antimicrob. Agents Chemother. 2004, 48, 2061-2068. [CrossRef]

17. Campion, J.J.; McNamara, P.J.; Evans, M.E. Pharmacodynamic modeling of ciprofloxacin resistance in Staphylococcus aureus. Antimicrob. Agents Chemother. 2005, 49, 209-219. [CrossRef]

18. Nielsen, E.I.; Viberg, A.; Löwdin, E.; Cars, O.; Karlsson, M.O.; Sandström, M. Semimechanistic pharmacokinetic/pharmacodynamic model for assessment of activity of antibacterial agents from time-kill curve experiments. Antimicrob. Agents Chemother. 2007, 51, 128-136. [CrossRef]

19. Sykes, R. The 2009 Garrod lecture: The evolution of antimicrobial resistance: A Darwinian perspective. J. Antimicrob. Chemother. 2010, 65, 1842-1852. [CrossRef]

20. Czock, D.; Keller, F. Mechanism-based pharmacokinetic-pharmacodynamic modeling of antimicrobial drug effects. J. Pharmacokinet. Pharmacodyn. 2007, 34, 727-751. [CrossRef]

21. Lewis, K. Persister cells, dormancy and infectious disease. Nat. Reviews. Microbiol. 2007, 5, 48-56. [CrossRef]

22. Khan, D.D.; Lagerbäck, P.; Cao, S.; Lustig, U.; Nielsen, E.I.; Cars, O.; Hughes, D.; Andersson, D.I.; Friberg, L.E. A mechanism-based pharmacokinetic/pharmacodynamic model allows prediction of antibiotic killing from MIC values for WT and mutants. J. Antimicrob. Chemother. 2015, 70, 3051-3060. [CrossRef]

23. Hall-Stoodley, L.; Costerton, J.W.; Stoodley, P. Bacterial biofilms: From the natural environment to infectious diseases. Nat. Reviews. Microbiol. 2004, 2, 95-108. [CrossRef] [PubMed]

24. Sou, T.; Kukavica-Ibrulj, I.; Levesque, R.C.; Friberg, L.E.; Bergström, C.A.S. Model-Informed Drug Development in Pulmonary Delivery: Semimechanistic Pharmacokinetic-Pharmacodynamic Modeling for Evaluation of Treatments against Chronic Pseudomonas aeruginosa Lung Infections. Mol. Pharm. 2020, 17, 1458-1469. [CrossRef]

25. Downing, K.J.; Mischenko, V.V.; Shleeva, M.O.; Young, D.I.; Young, M.; Kaprelyants, A.S.; Apt, A.S.; Mizrahi, V. Mutants of Mycobacterium tuberculosis lacking three of the five rpf-like genes are defective for growth in vivo and for resuscitation in vitro. Infect. Immun. 2005, 73, 3038-3043. [CrossRef]

26. Chen, C.; Ortega, F.; Rullas, J.; Alameda, L.; Angulo-Barturen, I.; Ferrer, S.; Simonsson, U.S. The multistate tuberculosis pharmacometric model: A semi-mechanistic pharmacokinetic-pharmacodynamic model for studying drug effects in an acute tuberculosis mouse model. J. Pharmacokinet. Pharmacodyn. 2017, 44, 133-141. [CrossRef]

27. Jumbe, N.; Louie, A.; Leary, R.; Liu, W.; Deziel, M.R.; Tam, V.H.; Bachhawat, R.; Freeman, C.; Kahn, J.B.; Bush, K.; et al. Application of a mathematical model to prevent in vivo amplification of antibiotic-resistant bacterial populations during therapy. J. Clin. Investig. 2003, 112, 275-285. [CrossRef]

28. Erwin, S.; Foster, D.M.; Jacob, M.E.; Papich, M.G.; Lanzas, C. The effect of enrofloxacin on enteric Escherichia coli: Fitting a mathematical model to in vivo data. PLoS ONE 2020, 15, e0228138. [CrossRef] [PubMed]

29. Fernández, L.; Breidenstein, E.B.; Hancock, R.E. Creeping baselines and adaptive resistance to antibiotics. Drug Resist. Updates 2011, 14, 1-21. [CrossRef]

30. Tam, V.H.; Schilling, A.N.; Nikolaou, M. Modelling time-kill studies to discern the pharmacodynamics of meropenem. J. Antimicrob. Chemother. 2005, 55, 699-706. [CrossRef]

31. Mohamed, A.F.; Nielsen, E.I.; Cars, O.; Friberg, L.E. Pharmacokinetic-pharmacodynamic model for gentamicin and its adaptive resistance with predictions of dosing schedules in newborn infants. Antimicrob. Agents Chemother. 2012, 56, 179-188. [CrossRef]

32. Nguyen, T.H.; Mouksassi, M.S.; Holford, N.; Al-Huniti, N.; Freedman, I.; Hooker, A.C.; John, J.; Karlsson, M.O.; Mould, D.R.; Pérez Ruixo, J.J.; et al. Model Evaluation of Continuous Data Pharmacometric Models: Metrics and Graphics. CPT Pharmacomet. Syst. Pharmacol. 2017, 6, 87-109. [CrossRef] [PubMed]

33. Bulitta, J.B.; Yang, J.C.; Yohonn, L.; Ly, N.S.; Brown, S.V.; D’Hondt, R.E.; Jusko, W.J.; Forrest, A.; Tsuji, B.T. Attenuation of colistin bactericidal activity by high inoculum of Pseudomonas aeruginosa characterized by a new mechanism-based population pharmacodynamic model. Antimicrob. Agents Chemother. 2010, 54, 2051-2062. [CrossRef] [PubMed] 
34. Thorsted, A.; Tano, E.; Kaivonen, K.; Sjölin, J.; Friberg, L.E.; Nielsen, E.I. Extension of Pharmacokinetic/Pharmacodynamic Time-Kill Studies To Include Lipopolysaccharide/Endotoxin Release from Escherichia coli Exposed to Cefuroxime. Antimicrob. Agents Chemother. 2020, 64, 4. [CrossRef]

35. Fontana, J.M.; Alexander, E.; Salvatore, M. Translational research in infectious disease: Current paradigms and challenges ahead Transl. Res. 2012, 159, 430-453. [CrossRef] [PubMed]

36. Diep, J.K.; Russo, T.A.; Rao, G.G. Mechanism-Based Disease Progression Model Describing Host-Pathogen Interactions During the Pathogenesis of Acinetobacter baumannii Pneumonia. CPT Pharmacomet. Syst. Pharmacol. 2018, 7, 507-516. [CrossRef] [PubMed]

37. Fors, J.; Strydom, N.; Fox, W.S.; Keizer, R.J.; Savic, R.M. Mathematical model and tool to explore shorter multi-drug therapy options for active pulmonary tuberculosis. PLoS Comput. Biol. 2020, 16, e1008107. [CrossRef]

38. Thorsted, A.; Nielsen, E.I.; Friberg, L.E. Pharmacodynamics of immune response biomarkers of interest for evaluation of treatment effects in bacterial infections. Int. J. Antimicrob. Agents 2020, 56, 106059. [CrossRef]

39. Sy, S.K.B.; Zhuang, L.; Xia, H.; Beaudoin, M.E.; Schuck, V.J.; Nichols, W.W.; Derendorf, H. A mathematical model-based analysis of the time-kill kinetics of ceftazidime/avibactam against Pseudomonas aeruginosa. J. Antimicrob. Chemother. 2018, 73, 1295-1304. [CrossRef]

40. Nielsen, E.I.; Cars, O.; Friberg, L.E. Predicting in vitro antibacterial efficacy across experimental designs with a semimechanistic pharmacokinetic-pharmacodynamic model. Antimicrob. Agents Chemother. 2011, 55, 1571-1579. [CrossRef] [PubMed]

41. Landersdorfer, C.B.; Rees, V.E.; Yadav, R.; Rogers, K.E.; Kim, T.H.; Bergen, P.J.; Cheah, S.E.; Boyce, J.D.; Peleg, A.Y.; Oliver, A.; et al. Optimization of a Meropenem-Tobramycin Combination Dosage Regimen against Hypermutable and Nonhypermutable Pseudomonas aeruginosa via Mechanism-Based Modeling and the Hollow-Fiber Infection Model. Antimicrob. Agents Chemother. 2018, 62, e02055-17. [CrossRef]

42. Sadiq, M.W.; Nielsen, E.I.; Khachman, D.; Conil, J.M.; Georges, B.; Houin, G.; Laffont, C.M.; Karlsson, M.O.; Friberg, L.E. A whole-body physiologically based pharmacokinetic (WB-PBPK) model of ciprofloxacin: A step towards predicting bacterial killing at sites of infection. J. Pharmacokinet. Pharmacodyn. 2017, 44, 69-79. [CrossRef]

43. Sy, S.K.B.; Zhuang, L.; Xia, H.; Schuck, V.J.; Nichols, W.W.; Derendorf, H. A model-based analysis of pharmacokineticpharmacodynamic (PK/PD) indices of avibactam against Pseudomonas aeruginosa. Clin. Microbiol. Infect. 2019, 25, 904.e9-904.e16. [CrossRef] [PubMed]

44. Kuepfer, L.; Niederalt, C.; Wendl, T.; Schlender, J.F.; Willmann, S.; Lippert, J.; Block, M.; Eissing, T.; Teutonico, D. Applied Concepts in PBPK Modeling: How to Build a PBPK/PD Model. CPT Pharmacomet. Syst. Pharmacol. 2016, 5, 516-531. [CrossRef]

45. Lin, Y.W.; Zhou, Q.T.; Han, M.L.; Onufrak, N.J.; Chen, K.; Wang, J.; Forrest, A.; Chan, H.K.; Li, J. Mechanism-Based Pharmacokinetic/Pharmacodynamic Modeling of Aerosolized Colistin in a Mouse Lung Infection Model. Antimicrob. Agents Chemother. 2018, 62, e01965-17. [CrossRef] [PubMed]

46. Tam, V.H.; Kabbara, S.; Vo, G.; Schilling, A.N.; Coyle, E.A. Comparative pharmacodynamics of gentamicin against Staphylococcus aureus and Pseudomonas aeruginosa. Antimicrob. Agents Chemother. 2006, 50, 2626-2631. [CrossRef]

47. Tam, V.H.; Ledesma, K.R.; Vo, G.; Kabbara, S.; Lim, T.P.; Nikolaou, M. Pharmacodynamic modeling of aminoglycosides against Pseudomonas aeruginosa and Acinetobacter baumannii: Identifying dosing regimens to suppress resistance development. Antimicrob. Agents Chemother. 2008, 52, 3987-3993. [CrossRef]

48. Zhuang, L.; He, Y.; Xia, H.; Liu, Y.; Sy, S.K.; Derendorf, H. Gentamicin dosing strategy in patients with end-stage renal disease receiving haemodialysis: Evaluation using a semi-mechanistic pharmacokinetic/pharmacodynamic model. J. Antimicrob. Chemother. 2016, 71, 1012-1021. [CrossRef]

49. Bulitta, J.B.; Ly, N.S.; Landersdorfer, C.B.; Wanigaratne, N.A.; Velkov, T.; Yadav, R.; Oliver, A.; Martin, L.; Shin, B.S.; Forrest, A.; et al. Two mechanisms of killing of Pseudomonas aeruginosa by tobramycin assessed at multiple inocula via mechanism-based modeling. Antimicrob. Agents Chemother. 2015, 59, 2315-2327. [CrossRef] [PubMed]

50. Kristoffersson, A.N.; David-Pierson, P.; Parrott, N.J.; Kuhlmann, O.; Lave, T.; Friberg, L.E.; Nielsen, E.I. Simulation-Based Evaluation of PK/PD Indices for Meropenem Across Patient Groups and Experimental Designs. Pharm. Res. 2016, 33, 1115-1125. [CrossRef]

51. Mohamed, A.F.; Kristoffersson, A.N.; Karvanen, M.; Nielsen, E.I.; Cars, O.; Friberg, L.E. Dynamic interaction of colistin and meropenem on a WT and a resistant strain of Pseudomonas aeruginosa as quantified in a PK/PD model. J. Antimicrob. Chemother. 2016, 71, 1279-1290. [CrossRef]

52. Ungphakorn, W.; Tängdén, T.; Sandegren, L.; Nielsen, E.I. A pharmacokinetic-pharmacodynamic model characterizing the emergence of resistant Escherichia coli subpopulations during ertapenem exposure. J. Antimicrob. Chemother. 2016, 71, $2521-2533$. [CrossRef]

53. Barbour, A.M.; Schmidt, S.; Zhuang, L.; Rand, K.; Derendorf, H. Application of pharmacokinetic/pharmacodynamic modelling and simulation for the prediction of target attainment of ceftobiprole against meticillin-resistant Staphylococcus aureus using minimum inhibitory concentration and time-kill curve based approaches. Int. J. Antimicrob. Agents 2014, 43, 60-67. [CrossRef] [PubMed] 
54. Iqbal, K.; Broeker, A.; Nowak, H.; Rahmel, T.; Nussbaumer-Pröll, A.; Österreicher, Z.; Zeitlinger, M.; Wicha, S.G. A pharmacometric approach to define target site-specific breakpoints for bacterial killing and resistance suppression integrating microdialysis, time-kill curves and heteroresistance data: A case study with moxifloxacin. Clin. Microbiol. Infect. 2020, 26, 1255.e1-1255.e8. [CrossRef] [PubMed]

55. Chung, P.; McNamara, P.J.; Campion, J.J.; Evans, M.E. Mechanism-based pharmacodynamic models of fluoroquinolone resistance in Staphylococcus aureus. Antimicrob. Agents Chemother. 2006, 50, 2957-2965. [CrossRef] [PubMed]

56. Grégoire, N.; Raherison, S.; Grignon, C.; Comets, E.; Marliat, M.; Ploy, M.C.; Couet, W. Semimechanistic pharmacokineticpharmacodynamic model with adaptation development for time-kill experiments of ciprofloxacin against Pseudomonas aeruginosa. Antimicrob. Agents Chemother. 2010, 54, 2379-2384. [CrossRef] [PubMed]

57. Mohamed, A.F.; Cars, O.; Friberg, L.E. A pharmacokinetic/pharmacodynamic model developed for the effect of colistin on Pseudomonas aeruginosa in vitro with evaluation of population pharmacokinetic variability on simulated bacterial killing. $J$. Antimicrob. Chemother. 2014, 69, 1350-1361. [CrossRef]

58. Pelligand, L.; Lees, P.; Sidhu, P.K.; Toutain, P.L. Semi-Mechanistic Modeling of Florfenicol Time-Kill Curves and in silico Dose Fractionation for Calf Respiratory Pathogens. Front. Microbiol. 2019, 10, 1237. [CrossRef]

59. Nguyen, K.; Bensman, T.J.; Wei, X.T.; Moore, J.N. Semimechanistic Modeling of Eravacycline Pharmacodynamics Using In Vitro Time-Kill Data with MIC Incorporated in an Adaptive Resistance Function. Antimicrob. Agents Chemother. 2020, 64, e01308-20. [CrossRef]

60. Zhao, C.; Wistrand-Yuen, P.; Lagerbäck, P.; Tängdén, T.; Nielsen, E.I.; Friberg, L.E. Combination of polymyxin B and minocycline against multidrug-resistant Klebsiella pneumoniae: Interaction quantified by pharmacokinetic/pharmacodynamic modelling from in vitro data. Int. J. Antimicrob. Agents 2020, 55, 105941. [CrossRef]

61. Aranzana-Climent, V.; Buyck, J.M.; Smani, Y.; Pachón-Diaz, J.; Marchand, S.; Couet, W.; Grégoire, N. Semi-mechanistic PK/PD modelling of combined polymyxin B and minocycline against a polymyxin-resistant strain of Acinetobacter baumannii. Clin. Microbiol. Infect. 2020, 26, 1254.e9-1254.e15. [CrossRef] [PubMed]

62. Brill, M.J.E.; Kristoffersson, A.N.; Zhao, C.; Nielsen, E.I.; Friberg, L.E. Semi-mechanistic pharmacokinetic-pharmacodynamic modelling of antibiotic drug combinations. Clin. Microbiol. Infect. 2018, 24, 697-706. [CrossRef]

63. Drug Disease Model Resources (DDMoRe) Foundation. Available online: www.ddmore.foundation (accessed on 6 January 2022).

64. Nguyen, T.T.; Guedj, J.; Chachaty, E.; de Gunzburg, J.; Andremont, A.; Mentré, F. Mathematical modeling of bacterial kinetics to predict the impact of antibiotic colonic exposure and treatment duration on the amount of resistant enterobacteria excreted. PLoS Comput. Biol. 2014, 10, e1003840. [CrossRef] [PubMed]

65. Ahmad, A.; Zachariasen, C.; Christiansen, L.E.; Græsbøll, K.; Toft, N.; Matthews, L.; Nielsen, S.S.; Olsen, J.E. Modeling the growth dynamics of multiple Escherichia coli strains in the pig intestine following intramuscular ampicillin treatment. BMC Microbiol. 2016, 16, 205. [CrossRef] [PubMed]

66. Rowland Yeo, K.; Hennig, S.; Krishnaswami, S.; Strydom, N.; Ayyar, V.S.; French, J.; Sinha, V.; Sobie, E.; Zhao, P.; Friberg, L.E.; et al. CPT: Pharmacometrics \& Systems Pharmacology-Inception, Maturation, and Future Vision. CPT Pharmacomet. Syst. Pharmacol. 2021, 10, 649-657. 